NISTIR 7900

\title{
Thermal Analysis of a Small Pharmaceutical Refrigerator for Vaccine Storage
}

\author{
Michal Chojnacky \\ Wyatt Miller \\ Gregory Strouse
}

http://dx.doi.org/10.6028/NIST.IR.7900

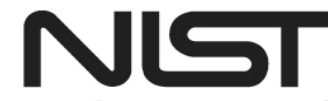

National Institute of Standards and Technology U.S. Department of Commerce 
NISTIR 7900

\title{
Thermal Analysis of a Small Pharmaceutical Refrigerator for Vaccine Storage
}

\author{
Michal Chojnacky \\ Wyatt Miller \\ Gregory Strouse \\ Sensor Science Division \\ Physical Measurement Laboratory
}

http://dx.doi.org/10.6028/NIST.IR.7900

November 2012

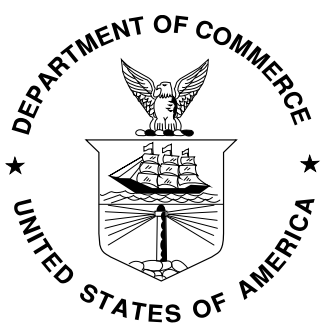

U.S. Department of Commerce Rebecca Blank, Acting Secretary

National Institute of Standards and Technology Patrick D. Gallagher, Under Secretary of Commerce for Standards and Technology and Director 


\section{ABSTRACT}

Each year, billions of dollars of vaccines are stored in refrigerators at the facilities of a variety of medical providers. Many vaccines must be maintained in the range $2{ }^{\circ} \mathrm{C}$ to $8{ }^{\circ} \mathrm{C}$ to retain product potency. As an extension to our study of household and pharmaceutical-grade refrigerator models used for this purpose [1,2], we have evaluated the performance of a small, under-thecounter pharmaceutical refrigerator model for vaccine storage use. The test unit [capacity = $\left.0.138 \mathrm{~m}^{3}(4.9 \mathrm{cu} \mathrm{ft})\right]$ proved fully adequate at maintaining vial temperatures within the desired $2{ }^{\circ} \mathrm{C}$ to $8{ }^{\circ} \mathrm{C}$ range, independent of how the refrigerator was loaded and under variable use and environmental conditions.

\section{EXPERIMENTAL METHOD}

In this study, we have evaluated the performance of a small, under-the-counter pharmaceutical refrigerator for vaccine storage use. This study supplements our previous refrigerator studies of dormitory-style, freezer-less, dual-zone and large pharmaceutical grade refrigerator units [1,2]. We have followed the same approach as in our preceding studies, installing 19 NIST-calibrated, Teflon-insulated, Type $\mathrm{T}$ thermocouples in various locations inside the refrigerator to determine the spatial temperature distribution throughout the unit's interior. As before, thermocouples were attached to refrigerator walls or storage trays, hung in the air, mounted inside of glycol-filled bottles, and taped to actual vaccine vials. We also placed five digital data logging thermometers in various locations inside the refrigerator. The thermocouple and data logger installation pattern is shown in Fig. 1 below. Table 1 summarizes the equipment used for this study.
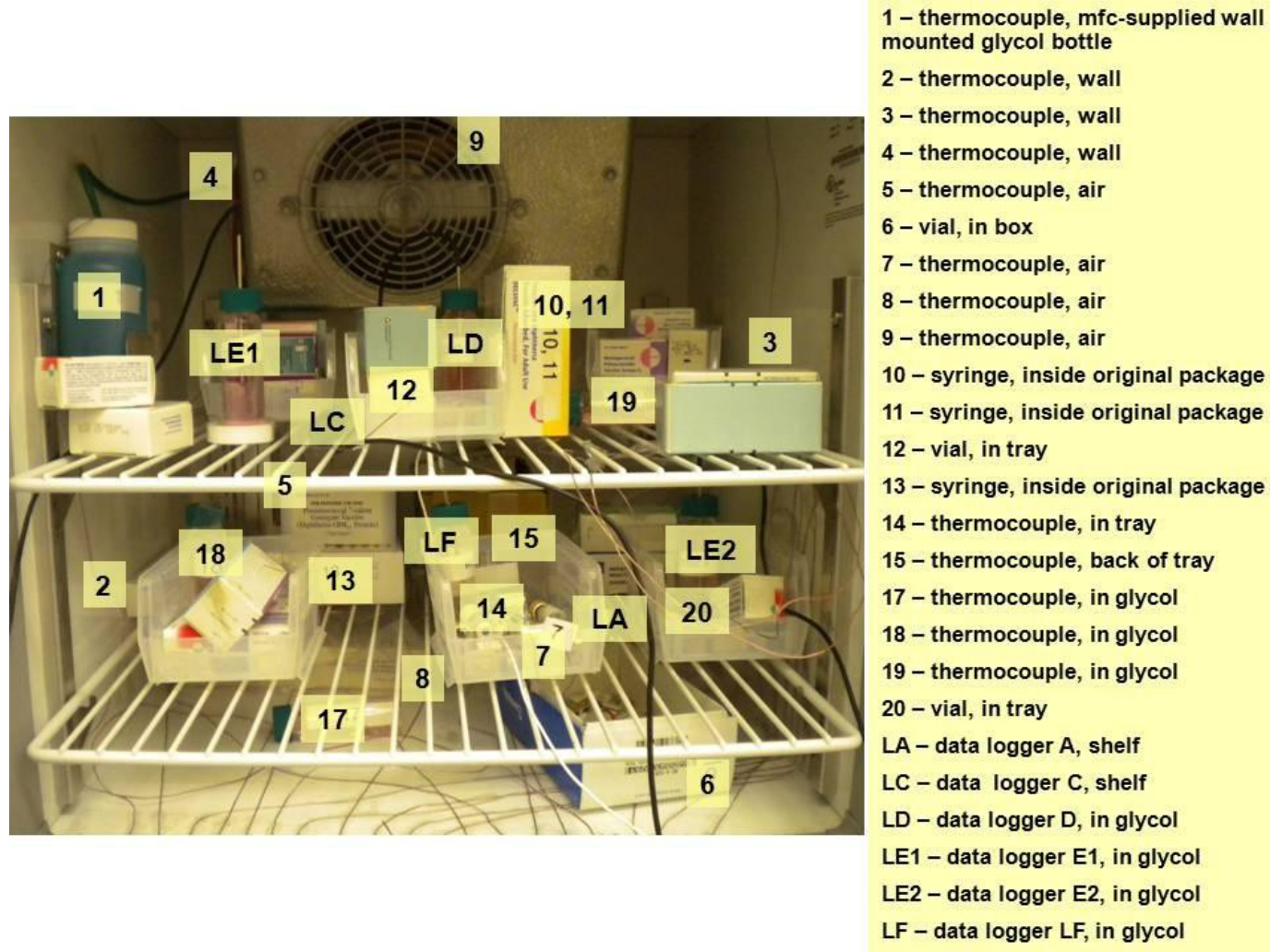

Fig. 1. Thermocouple and data logger installation pattern. 
Table 1. Equipment used for the study.

\begin{tabular}{|c|c|}
\hline Equipment name: & Specifications: \\
\hline $\begin{array}{l}\text { Under-the-counter } \\
\text { Pharmaceutical Refrigerator }\end{array}$ & $\begin{array}{l}\text { - Fully automatic cycle defrost refrigerator }(115 \mathrm{~V}) \\
\text { - } \text { Height: } 0.508 \mathrm{~m} \\
\text { - } \text { Didth: } 0.508 \mathrm{~m} \\
\text { - } \quad \text { Capacity: } 0.138 \mathrm{~m}^{3}(4.9 \mathrm{cu} \mathrm{ft}) \\
\text { - } \text { Positive, forced air circulation } \\
\text { - } \text { Electronic control system and digital thermometer } \\
\text { - } \text { Out-of-range temperature alarm }\end{array}$ \\
\hline Plastic trays & - $\quad$ Stacking plastic storage trays/ bins \\
\hline 19 thermocouples & $\begin{array}{ll}\text { - } & \text { Type } \mathrm{T} \text { (copper-constantan) } \\
\text { - } & 0.5 \mathrm{~mm} \text { diameter, } 1.83 \mathrm{~m} \text { length } \\
\text { - } & \text { Teflon insulation } \\
\text { - } & \text { Calibrated at } 0{ }^{\circ} \mathrm{C} \\
\text { - } & \text { Uncertainty }(\mathrm{k}=2): \pm 0.12^{\circ} \mathrm{C}\end{array}$ \\
\hline Data logger A & 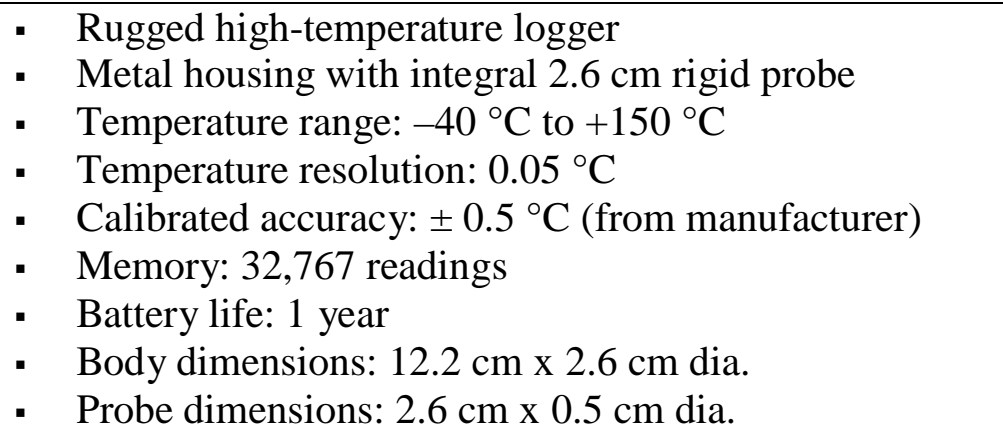 \\
\hline Data logger C & $\begin{array}{l}\text { - } \text { Plastic-housing temperature and humidity logger } \\
\text { - Temperature range: }-35^{\circ} \mathrm{C} \text { to } 80^{\circ} \mathrm{C} \\
\text { - } \quad \text { Temperature resolution: } 0.5^{\circ} \mathrm{C} \\
\text { - } \\
\text { - } \text { Accuracy: } \pm 0.3{ }^{\circ} \mathrm{C} \text { (manufacturer rating) } \\
\text { - } \quad \text { Battery life: } 1 \text { year } \\
\text { - } \quad \text { Nominal body dimensions: } 10.2 \mathrm{~cm} \text { x } 2.3 \mathrm{~cm} \text { max dia. }\end{array}$ \\
\hline Data logger D & 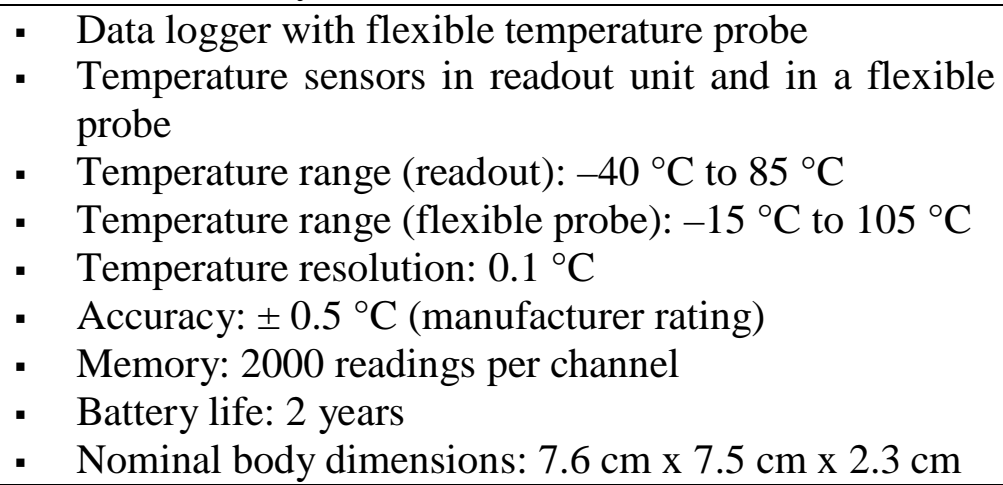 \\
\hline Data logger E1, E2 & $\begin{array}{l}\text { - Data logger with two flexible temperature probes } \\
\text { - Temperature sensors in flexible probes } \\
\text { - Temperature range: }-15^{\circ} \mathrm{C} \text { to } 105^{\circ} \mathrm{C}\end{array}$ \\
\hline
\end{tabular}




\begin{tabular}{|c|c|}
\hline & $\begin{array}{ll}\text { - } & \text { Temperature resolution: } 0.1^{\circ} \mathrm{C} \\
\text { - } & \text { Accuracy: } \pm 0.5^{\circ} \mathrm{C} \text { (manufacturer rating) } \\
\text { - } & \text { Memory: } 2000 \text { readings per channel } \\
\text { - } & \text { Battery life: } 2 \text { years } \\
\text { - } & \text { Nominal body dimensions: } 7.6 \mathrm{~cm} \text { x } 7.5 \mathrm{~cm} \text { x } 2.3 \mathrm{~cm} \\
\end{array}$ \\
\hline Data logger $F$ & $\begin{array}{l}\text { - Wireless data recorder with external data logger } \\
\text { unit/temperature sensor } \\
\text { - } \text { Data logger features flexible temperature probe and } \\
\text { readout unit } \\
\text { - } \text { Temperature range: }-60^{\circ} \mathrm{C} \text { to } 155^{\circ} \mathrm{C} \\
\text { - } \text { Temperature resolution: } 0.1^{\circ} \mathrm{C} \\
\text { - } \text { Accuracy: } \pm 0.3^{\circ} \mathrm{C} \text { from }-20^{\circ} \mathrm{C} \text { to } 80^{\circ} \mathrm{C} \text { (mfc rating) } \\
\text { - } \text { Memory: } 16,000 \text { readings } \\
\text { - } \text { Battery life: } 6 \text { months } \\
\text { - Nominal body dimensions: } 6.2 \mathrm{~cm} \times 4.7 \mathrm{~cm} \mathrm{x} 1.9 \mathrm{~cm} \\
\text { - } \text { Wireless data transmission distance: Up to } 100 \text { Meters } \\
\text { (Line of Sight and No Obstructions) }\end{array}$ \\
\hline $\begin{array}{l}\text { Thermocouple measurement } \\
\text { system }\end{array}$ & - 6.5 digit multimeter with scanner \\
\hline
\end{tabular}

Following data logger and thermocouple installation, the small pharmaceutical refrigerator was subjected to a number of use patterns designed to replicate the range of vaccine storage conditions that regularly occur in Vaccines for Children (VFC) provider offices. A complete listing of the different trials and order in which they were performed is contained in the measurement matrix (Table 2) below. In our previous studies, we found changing the vaccine storage method (e.g. plastic trays vs. cardboard boxes, or a mix of both) has minimal or indeterminate impact on a refrigerator's ability to maintain vaccine storage temperatures. As a result, we have eliminated packing method variation trials from this study.

Table 2. Matrix of measurements performed for the study.

\begin{tabular}{|c|c|c|c|c|}
\hline Trial & \multicolumn{3}{|c|}{ Load Density } & Measurement Parameters \\
& Low & Medium & High & Normal \\
\hline 1 & & $\mathrm{x}$ & & Normal \\
\hline 2 & $\mathrm{x}$ & & & Normal \\
\hline 3 & & $\mathrm{x}$ & & Normal \\
\hline 4 & & & $\mathrm{x}$ & increase room temp \\
\hline 5 & & & $\mathrm{x}$ & periodic door opening \\
\hline 6 & & & $\mathrm{x}$ & Normal \\
\hline 7 & & & $\mathrm{x}$ & increase room temp \\
\hline 8 & & $\mathrm{x}$ & & periodic door opening \\
\hline 9 & & $\mathrm{x}$ & & power off \\
\hline 10 & & $\mathrm{x}$ & & \\
\hline 11 & & $\mathrm{x}$ & & \\
\hline
\end{tabular}


In general, each trial was started during the afternoon, and measurements were recorded overnight and into the next morning. On average, we recorded 16 to $24 \mathrm{~h}$ of data for each trial, although some trials were continued over the course of several days. The only exception to this was the door opening trials, which only lasted 4 to $5 \mathrm{~h}$. The thermocouple measurement system records readings once every $10 \mathrm{~s}$. The individual data loggers can be set to various reading rates. In general, the loggers were set to record once every minute, except for logger $\mathrm{F}$, which recorded at $30 \mathrm{~s}$ intervals. During the door opening trials, we increased the reading rate to once every $10 \mathrm{~s}$ to $42 \mathrm{~s}$ (depending on the capabilities of the logger).

\section{INTERPRETATION OF RESULTS}

\subsection{Effect of loading density}

In trials performed using this refrigerator model, vaccine storage density did not appear to have a major impact on the refrigerator's ability to maintain the desired temperature range. The photographs below (Fig. 2) show the various levels of packing density tested.

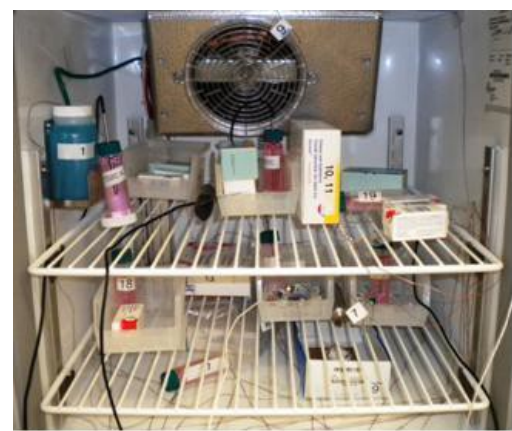

Low Density Pack

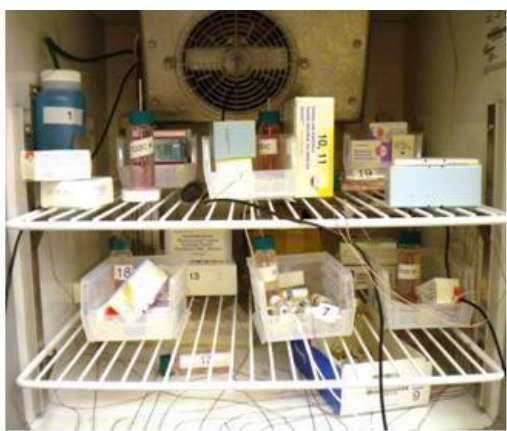

Medium Density Pack

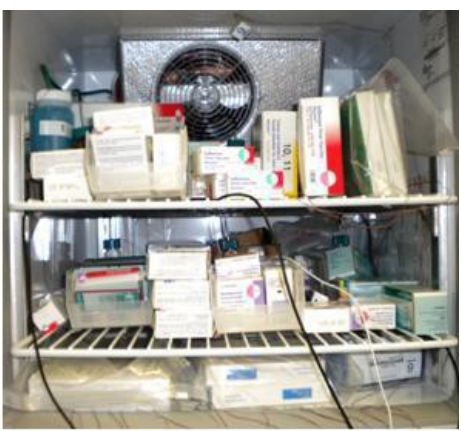

High Density Pack

Fig. 2. Typical packing patterns.

Average thermometer temperatures remained very stable throughout the study, showing minimal temperature variability in response to different loading densities (see Fig. 3). With the exception of 2 thermocouples (TC3 - wall, TC17 - floor), average thermometer temperatures shifted by less than $1{ }^{\circ} \mathrm{C}$ for the duration of the study, despite being subjected to low, medium, and high density packing loads. All of the thermometers maintained average temperatures well within the prescribed $2{ }^{\circ} \mathrm{C}$ to $8{ }^{\circ} \mathrm{C}$ range across all trials.

The two thermocouples that display slightly atypical behavior $(3,17)$ were both installed in locations that we have consistently seen to be poor indicators of properly stored vaccine temperatures - that is, on the refrigerator wall (3), and placed in direct contact with the refrigerator floor (17). 


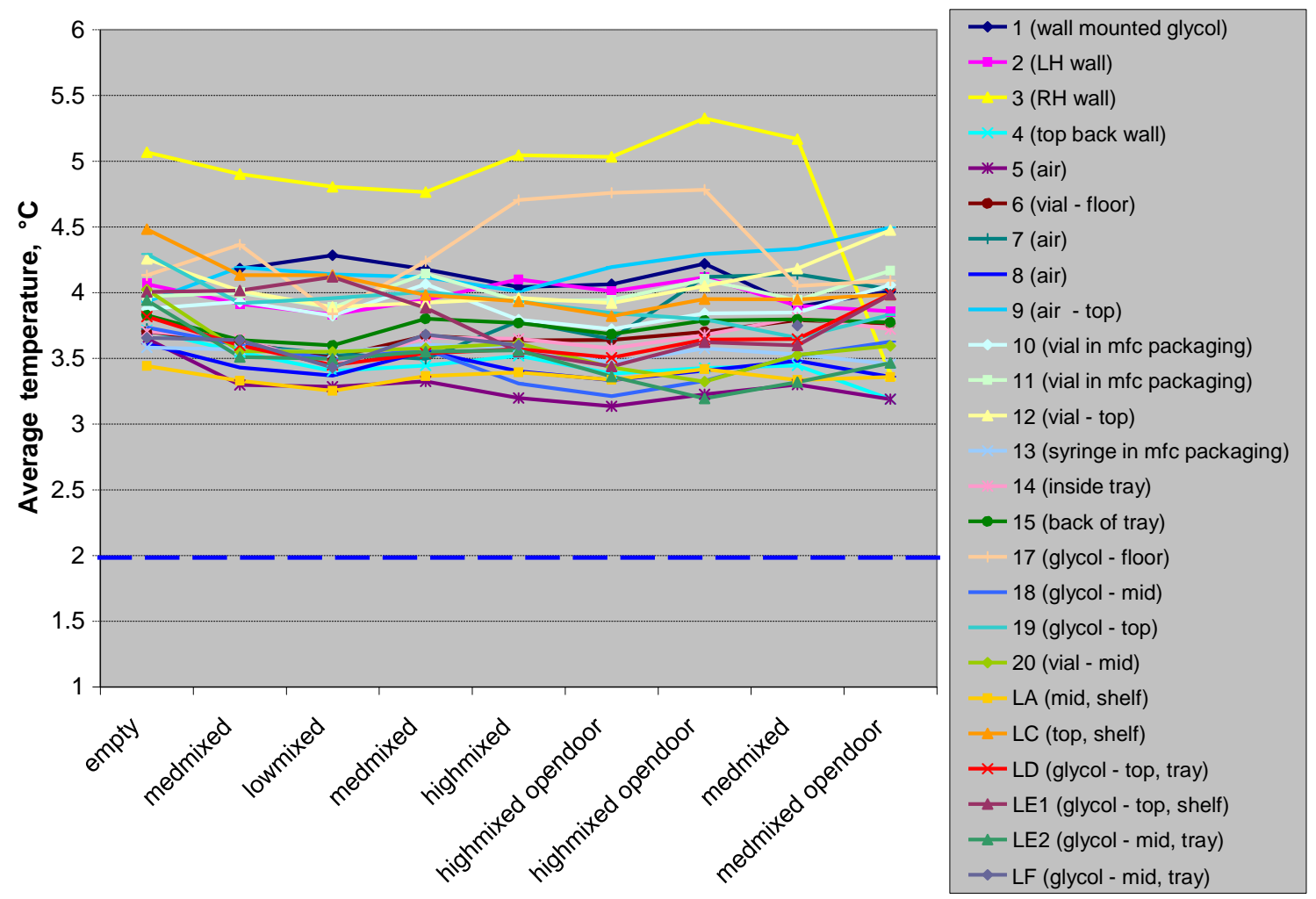

Figure 3. Average temperature of pharmaceutical refrigerator for all sensors, as a function of loading pattern. Labels on the abscissa correspond to entries in the measurement matrix of Table 1.

Figure 3 shows the average reading for each thermometer across all of the closed-door pharmaceutical refrigerator trials, as well as the periodic door-opening trials. Other than the two aberrant thermocouples discussed previously $(3,17)$, it is readily apparent that the main body of the refrigerator as well as the vaccine vials themselves stayed within a tightly-controlled temperature range, regardless of packing density variations. The high-performance features and small size of this unit minimize the presence of spatial temperature variations within the refrigerator's interior. Nearly all of the sensors recorded average temperatures within a band of about $1{ }^{\circ} \mathrm{C}$ regardless of where they were located (e.g., top shelf, bottom shelf). For the duration of our testing (51 days), the vertical shift (e.g., drift) of this distribution was less than $0.5^{\circ} \mathrm{C}$. As such, it is clear that the small pharmaceutical refrigerator maintains stable set point control across the variable packing densities likely to occur in a vaccine storage system, and is more than sufficient for normal, refrigerated vaccine storage.

One feature which is not visible in the average temperatures summary graph (Fig. 3), is that while all of the mean thermocouple sensors remained within the specified $2{ }^{\circ} \mathrm{C}$ to $8{ }^{\circ} \mathrm{C}$ bounds, the steady state temperature oscillations of several air and wall TCs consistently dip below $2{ }^{\circ} \mathrm{C}$ during normal refrigerator operation. These oscillations occur in response to the refrigerator compressor timing and periodic circulation of cold air needed to maintain a stable set point temperature. Figures $4 \mathrm{a}$ and $4 \mathrm{~b}$ below show the thermocouple response to steady state refrigerator temperature oscillations. These graphs are representative of the standard temperature response observed during normal, closed-door operation throughout the course of our study. 

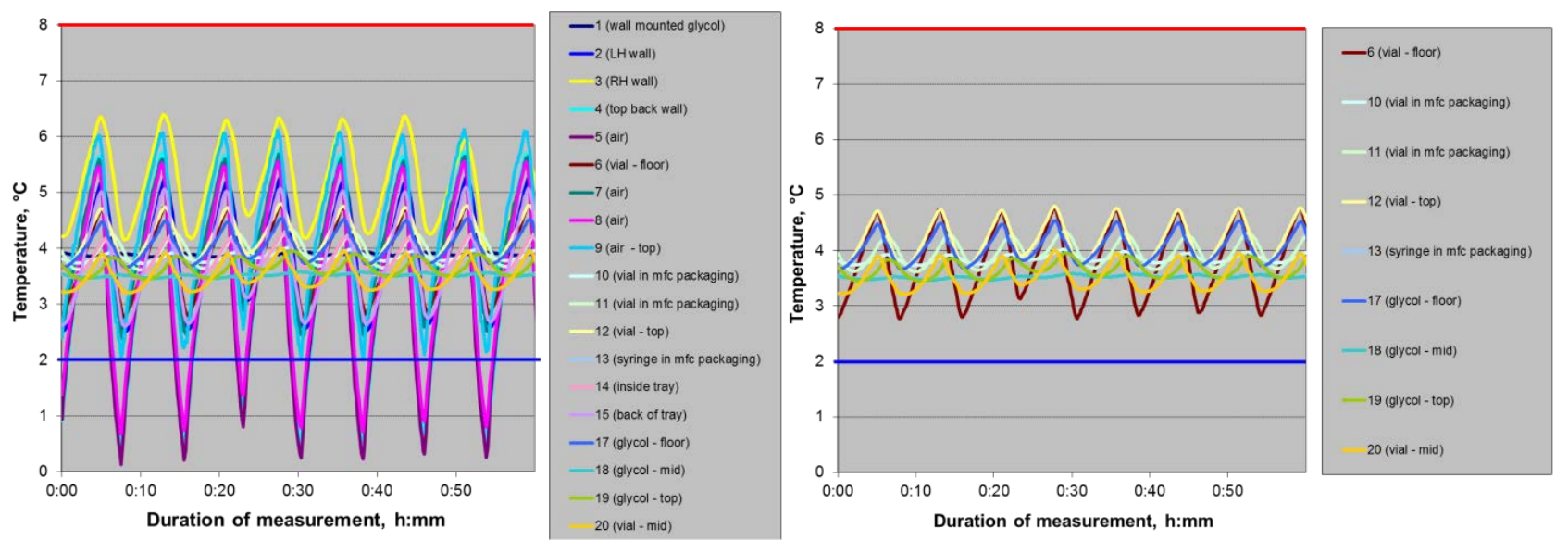

Fig. 4a. (Left) One hour sample of normal, closed-door refrigerator operation with medium density load, all thermocouples shown.

Fig. 4b. (Right) Same one hour sample of normal, closed-door refrigerator operation with medium density load, but only thermocouples attached to vials or inside glycol-filled bottles are shown.

The effect shown in figures $4 \mathrm{a}$ and $4 \mathrm{~b}$ highlights the importance of choosing the right location and installation method for vaccine temperature monitors. If we examine figure $4 \mathrm{~b}$, we can immediately see that all of thermocouples attached to vaccine vials remained well within the correct storage temperature range, as did the thermocouples kept inside glycol bottles, which give a good approximation of liquid vaccine temperature response. However, in figure 4a, we see that a number of thermocouples are registering minimum temperatures close to $0{ }^{\circ} \mathrm{C}$ every few minutes. Figure 5 below shows the same sample of data, but only thermocouples hanging in air and thermocouples in close proximity or direct contact with refrigerator walls are shown.

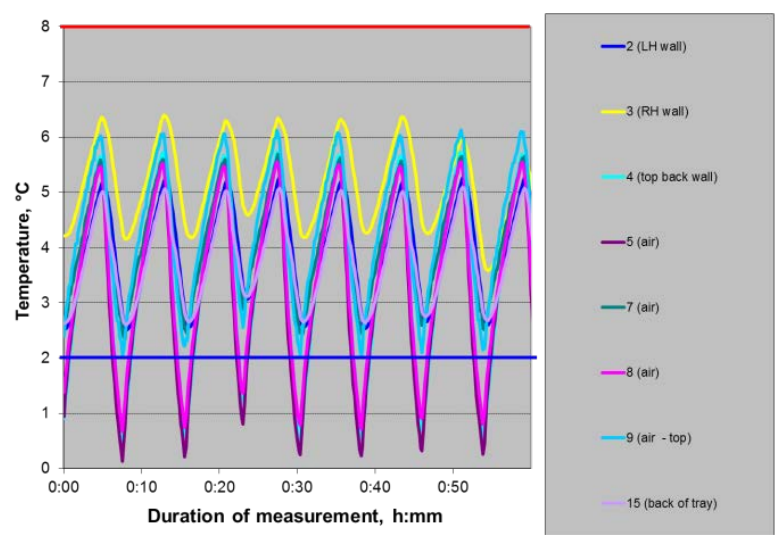

Fig. 5. One hour sample of data, thermocouples attached to/in close proximity to refrigerator walls or hanging in air are shown.

Clearly, thermometers placed in these locations (air, walls) experience much greater temperature fluctuations than the actual stored vaccine vials. This is consistent with the results we have seen 
in our studies of other refrigerator types. While the small pharmaceutical refrigerator exhibits extremely stable set point control and maintains stored items with minimal spatial temperature variation, the air inside the unit and the interior walls are subject to much larger temperature fluctuations. Relying on either of these locations as an indicator of stored vaccine temperature is a mistake, and will surely result in "false positive" out-of-range temperature alarms.

\subsection{Effect of door opening and closing-normal use simulation}

The results of the periodic door-opening trials also support the efficacy of the small pharmaceutical refrigerator model. The refrigerator's ability to maintain temperatures of stored vaccines and correctly installed thermometers was not impacted by our repeated, $15 \mathrm{~s}$ door opening pattern designed to simulate normal refrigerator use. As we saw during our closed-door refrigerator tests, thermocouples hanging in air or close to the refrigerator walls recorded out-ofrange temperatures. Periodic door opening exacerbated this effect by causing large spikes in air temperature (Fig. 6).

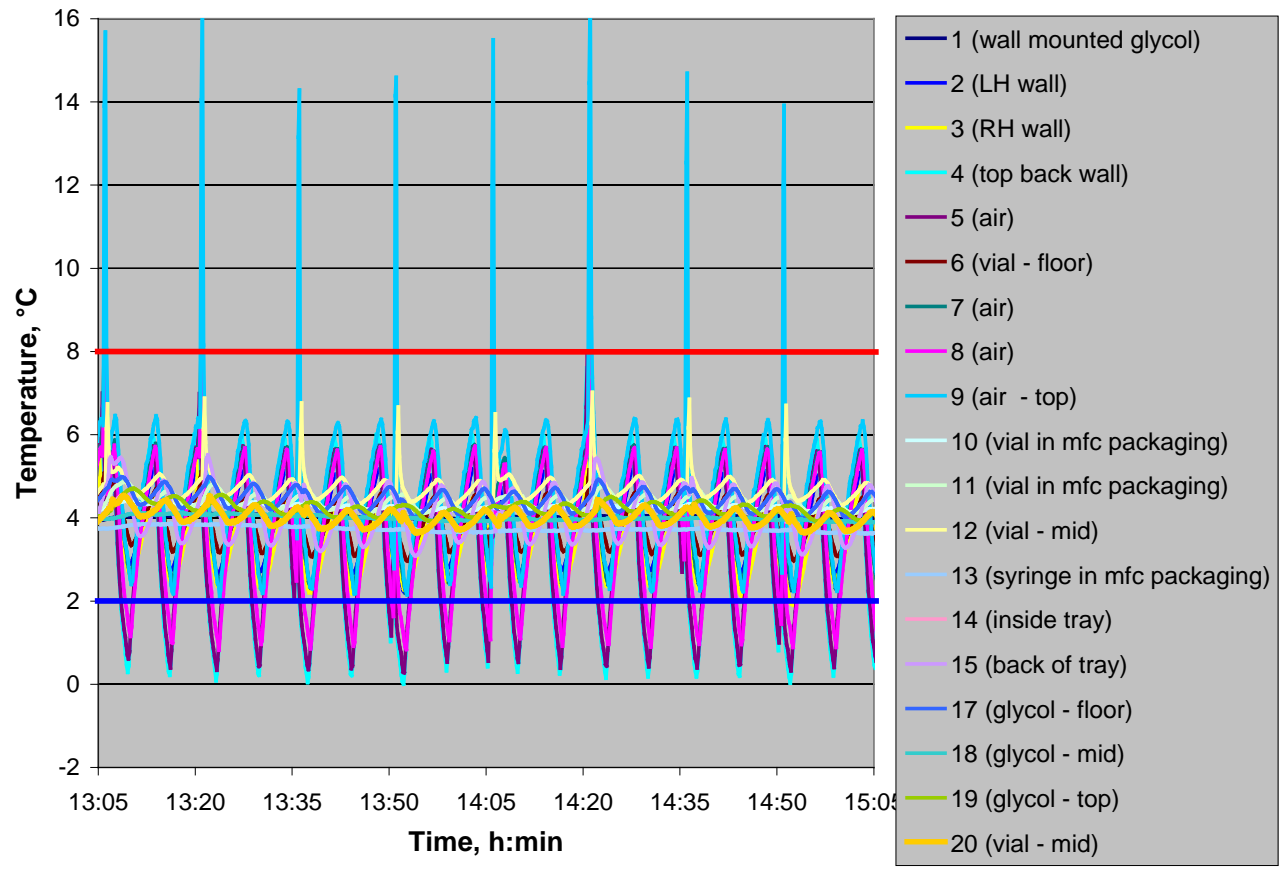

Fig. 6. Door opening trial using a medium density load, all thermocouples shown.

However, these spikes in air temperature did not impact the refrigerator's ability to properly maintain stored vaccine temperature. All of the remaining thermocouples (in trays, attached to vials, in glycol-filled bottles) and each of the electronic data loggers continued to record temperatures within the specified $2{ }^{\circ} \mathrm{C}$ to $8{ }^{\circ} \mathrm{C}$ range throughout the door-opening trials. To isolate the effects of door opening on vaccine vials and thermocouples kept in glycol, the data from these selected thermocouples only is shown in figure 7 below. 

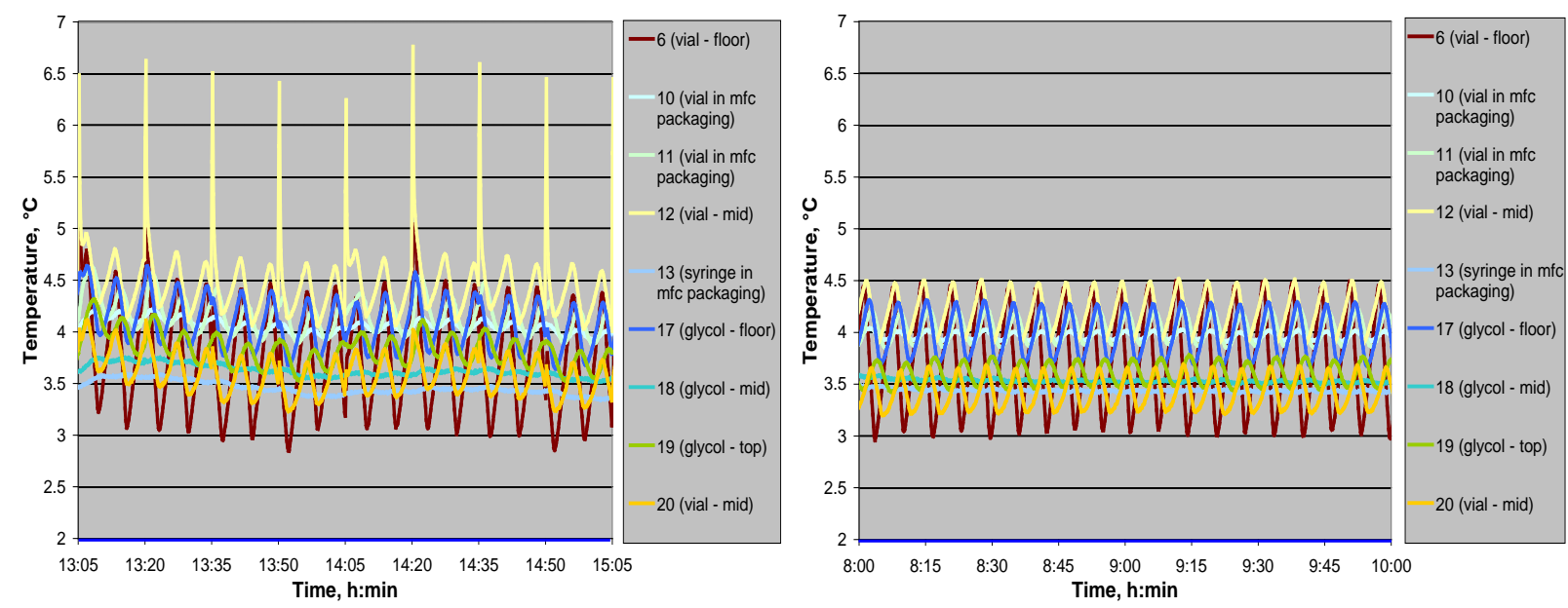

Fig. 7a. (Left) Door opening trial. Only thermocouples monitoring vial temperatures or inside glycol-filled bottles are shown.

Fig. 7b. (Right) Temperature response of same selected thermocouples, recorded $17 \mathrm{~h}$ later and with refrigerator door kept closed.

Figure 7a shows the selected thermometer responses to repeated door opening. For comparison, figure $7 \mathrm{~b}$ shows the closed-door, equilibrium temperature behavior of the same thermometers. While it is clear that the door opening does have some effect on stored vial temperature, this effect is storage method and location dependent, and ultimately is not significant enough to result in thermal excursions outside of $2{ }^{\circ} \mathrm{C}$ to $8{ }^{\circ} \mathrm{C}$. Only thermocouple 12 (attached to a vial) shows marked temperature spikes in response to door opening. However, this particular vial had been removed from its original cardboard packaging and was kept in an open tray. Removing vials from their packaging is not recommended by vaccine manufactures or in VFC guidelines, as the packaging helps to preserve temperature stability of the vial by adding a protective layer of thermal mass. Thermocouples 6 and 20 were also attached to similarly unpackaged vials, and as a result, show much larger temperature variations than the monitored vials and syringes kept inside their original boxes (TCs 10,11,13). Comparing the door opening data to the closed-door data, we can see that the small pharmaceutical refrigerator's performance is such that the impact of door opening on vial temperature is minimal. Even in the case of improperly stored vials (e.g., removed from packaging, placed on refrigerator floor), the small pharmaceutical refrigerator successfully maintains proper vaccine storage temperatures during normal door-opening use patterns.

Table 2 below summarizes the results of trials in which the refrigerator door was left ajar for $1 \mathrm{~h}$, showing the amount of time elapsed once the door was opened until the monitored vials exceeded the allowed maximum temperature of $8{ }^{\circ} \mathrm{C}$. These trials were conducted to maintain consistency with our previous refrigerator study methods. However, it should be noted that the specific small pharmaceutical refrigerator unit that we evaluated features a magnetic self-closing door. In reality, it would be quite difficult or impossible to "accidentally" leave the door of this particular unit ajar. For the purpose of these measurements, we intentionally propped the door open for $1 \mathrm{~h}$. 
Table 2. Time after opening door until vial temperature exceeded $8{ }^{\circ} \mathrm{C}$.

\begin{tabular}{|l|c|c|}
\hline $\begin{array}{c}\text { Name and Location } \\
\text { (mfc = manufacturer) }\end{array}$ & $\begin{array}{c}\text { High Density Mixed } \\
\text { (minutes) }\end{array}$ & $\begin{array}{c}\text { Medium Density Mixed } \\
\text { (minutes) }\end{array}$ \\
\hline vial 12 (in tray, top shelf) & 7 & did not exceed \\
vial 11 (inside mfc packaging) & 20 & did not exceed \\
vial 10 (inside mfc packaging) & did not exceed & did not exceed \\
vial 20 (in tray, middle shelf) & did not exceed & did not exceed \\
vial 13 (syringe in mfc packaging) & did not exceed & did not exceed \\
vial 6 (in tray, floor level) & did not exceed & did not exceed \\
\hline
\end{tabular}

For the most part, the refrigerator continued to maintain storage temperatures below $8{ }^{\circ} \mathrm{C}$ despite the continuous influx of ambient air through the open door. Drawing additional conclusions based on these results is difficult, especially given the fact that it is unlikely for this type of scenario (door "accidentally" propped open) to occur when using this small pharmaceutical refrigerator unit.

\subsection{Effect of Increasing Room Temperature}

To determine whether room temperature fluctuations impact the pharmaceutical refrigerator's ability to maintain its set point temperature, we performed three trials in which the room temperature was varied between $20^{\circ} \mathrm{C}$ and $25^{\circ} \mathrm{C}$. We can analyze the results by comparing the room temperature probe readings from logger $\mathrm{LD}$ to the refrigerator probe readings from $\mathrm{LD}$, LE1 and LE2. This analysis is summarized in table 3 below.

Table 3. Refrigerator probe temperature change relative to room temperature change $\left({ }^{\circ} \mathrm{C}\right)$

\begin{tabular}{|c|c|c|}
\hline Logger Name & High Density & Medium Density \\
\hline LD & 0.03 & 0.03 \\
LE1 & 0.02 & 0.03 \\
LE2 & 0.02 & 0.02 \\
\hline
\end{tabular}

Table 3 shows the temperature change recorded by each of the three refrigerator data logger probes scaled to the change in ambient temperature recorded by the main unit sensor, which was kept outside the refrigerator. So, for example, during the High Density trial, logger LE1 recorded a temperature increase of $0.02{ }^{\circ} \mathrm{C}$ for every one degree increase in room temperature. All three data logger probes recorded a temperature change of $0.03{ }^{\circ} \mathrm{C}$ or less per degree rise in room temperature. This effect is so small that it could be a product of extraneous factors rather the changing room temperature. If we assume these changes are in fact due to room temperature variation and that the relationship is linear, we would need to vary environmental conditions by $33{ }^{\circ} \mathrm{C}$ just to see a one degree change in internal refrigerator temperature.

The small pharmaceutical refrigerator's performance in these trials indicates that it should be able to withstand large ambient temperature changes while maintaining proper vaccine storage conditions in its interior. However, it must be emphasized that because our study only monitored the effects of a $5{ }^{\circ} \mathrm{C}$ room temperature change, we may not have captured additional thermal 
effects that could occur during much larger room temperature changes. The use of a continuous temperature monitoring system will allow workers to immediately identify any problem temperature effects resulting from different environmental conditions.

\subsection{Effect of a Power Outage}

To observe what occurs following a power outage, we performed two trials in which the closed refrigerator was unplugged and monitored overnight. In both trials, all of the thermometers recorded a fairly steep increase in temperature that slowed down slightly over time. All of the thermometers, including those attached to vaccine vials, exceeded the allowed maximum temperature within 1:16 h:min for the medium density trial, and within 2:25 h:min during the high density trial.

To determine the required response time to preserve vaccine viability during a power outage situation, we examined the amount of time elapsed from the point that the refrigerator was unplugged until the thermometers attached to vials exceeded $8{ }^{\circ} \mathrm{C}$. This information is reported in table 4 below.

Table 4. Time after power-off until vial temperature exceeded $8{ }^{\circ} \mathrm{C}$.

\begin{tabular}{|l|c|c|}
\hline $\begin{array}{c}\text { Name and Location } \\
\text { (mfc = manufacturer) }\end{array}$ & $\begin{array}{c}\text { High Density Mixed } \\
\text { (h:min) }\end{array}$ & $\begin{array}{c}\text { Medium Density Mixed } \\
\text { (h:min) }\end{array}$ \\
\hline vial 11 (inside mfc packaging) & $0: 35$ & $0: 33$ \\
vial 10 (inside mfc packaging) & $0: 53$ & $0: 48$ \\
vial 12 (in tray) & $1: 01$ & $0: 49$ \\
vial 6 (in tray) & $2: 09$ & $1: 00$ \\
vial 20 (in tray) & $2: 14$ & $1: 03$ \\
vial 13 (syringe in mfc packaging) & $2: 25$ & $1: 16$ \\
\hline
\end{tabular}

These results are similar to those obtained in power outage trials of the large pharmaceutical refrigerator unit [2]. During a power outage event, both the small and large pharmaceutical grade refrigerators warmed up to temperatures above $8{ }^{\circ} \mathrm{C}$ much more quickly than the household grade units that were tested. In the case of the large pharmaceutical grade refrigerator, we attributed this effect to the unit's sliding glass door, which provides minimal thermal insulation in comparison to the standard opaque doors featured in household refrigerator models. However, the small pharmaceutical refrigerator features an opaque door rather than the sliding glass type. It's possible that the unit's small size simply results in faster total equilibration time because there is a significantly less thermal mass to contend with in a $4.9 \mathrm{cu} \mathrm{ft}$ unit than in a $14 \mathrm{cu} \mathrm{ft}$ or $16 \mathrm{cu} \mathrm{ft}$ model. In this case, the reduced size means that the small pharmaceutical unit warms up to ambient temperature relatively quickly during a power outage event. To combat this potential weakness, users who opt to use this type of refrigerator model ideally should also select a robust continuous temperature monitoring system with wireless alarm capabilities. In the case of a thermal excursion, staff members receive electronic alarm notifications by email or phone. If a power outage occurs outside of normal business hours, workers receiving immediate alarm notifications may be able to implement a contingency plan in time to save the stored vaccines. 
Ultimately, it's important for users to be aware that vaccines stored in a small pharmaceutical refrigerator may be more susceptible to damage from a power outage than if stored in some other, larger type of refrigerator. Other performance considerations may still make the small pharmaceutical unit an attractive choice to certain types of users, so individual provider offices should evaluate their needs to determine what sorts of risks are most critical to their situation. If the office features a robust, back-up generator system, then power-outage susceptibility may not be a significant concern. In this case, the small size and excellent temperature set point control may outweigh the potential risk. By contrast, a different office with different circumstances may recognize that frequent power outages in their area pose a significant risk to stored vaccines, and therefore would choose to use a unit that demonstrates better insulation and resistance to external heating.

Recovery from an outage in which the small pharmaceutical refrigerator is allowed to reach ambient temperature requires $\sim 3 \mathrm{~h}$, regardless of refrigerator loading density. The refrigerator's small size means that the unit rapidly cools down and equilibrates to its pre-outage state.

\subsection{Defrost Cycle in the Small Pharmaceutical Refrigerator}

According to the manufacturer, defrosting of this unit is primarily accomplished by circulating air during off-cycle periods, and under normal conditions, the associated temperature increase is virtually unnoticeable. This is consistent with our findings, as we did not observe any temperature fluctuations occurring in response to a defrost cycle. However, the manufacturer notes that an occasional warm-up of $2{ }^{\circ} \mathrm{C}$ is possible under very high loads, heavy use, and/or extreme ambient conditions.

\subsection{General Stability of Vial Temperature and Suitability of Small Pharmaceutical Refrigerator Model for Maintenance of Vaccine Storage Conditions}

Our results indicate that the small pharmaceutical refrigerator model is suitable for vaccine storage. Vaccine vial temperatures remained within the specified $2{ }^{\circ} \mathrm{C}$ to $8{ }^{\circ} \mathrm{C}$ range throughout all of the packing variation trials, as well as during the 15 second door opening trials. Furthermore, average vial temperatures varied by less than $0.5^{\circ} \mathrm{C}$ throughout this entire range of testing. The small pharmaceutical refrigerator exhibits excellent long-term temperature stability, even under varying conditions. The unit also displays superior spatial thermal uniformity to that of household, consumer-grade refrigerators. With the exception of the interior walls and floor, average temperatures of stored vials and thermometers remained within a temperature band of $1^{\circ} \mathrm{C}$, regardless of exact location inside the unit.

\subsection{Proper Locations for Vial Storage in the Small Pharmaceutical Refrigerator}

Throughout the course of the closed-door pharmaceutical refrigerator trials, vaccine vials generally remained within the desired temperature range regardless of their location in the refrigerator. Only one monitored vial (6) recorded small thermal excursions of less than half a degree below $2{ }^{\circ} \mathrm{C}$ on two occasions. However, this particular vial was kept on the floor level of the unit. While the unit's user manual does not specify whether storage on the floor is acceptable, we have seen other manufacturers advise against this practice. In our previous studies, we 
observed that items stored in direct contact with the refrigerator floor frequently experienced aberrant temperature conditions as compared to items kept in the center of the unit. In addition, vial 6 was unpackaged from its original cardboard box, a practice that is discouraged in VFC guidelines and which we have observed to be problematic in previous refrigerator studies. All other vials remained within the specified temperature range and recorded zero excursions for the duration of testing, regardless of location or storage method. This refrigerator model is purposebuilt for vaccine storage. As a result, it features enhanced temperature set point control and more a sophisticated ventilation system than is included in most household refrigerator models.

Based on our studies, vaccine storage anywhere inside the small pharmaceutical refrigerator unit will result in appropriate storage temperatures provided that several storage conditions are met. These conditions hold true for ANY refrigerator model or type:

- Store vaccines on shelves in center of the refrigerator

- Do not place any vaccines in direct contact with refrigerator walls

- Do not store vaccines on the floor level

- Keep vaccines in original cardboard packaging, as supplied by manufacturer. If plastic trays are used to contain and organize vaccines, place vaccine boxes in trays. Do not store individual vials in the trays. 


\section{SUMMARY}

\begin{tabular}{|c|c|}
\hline \multicolumn{2}{|c|}{$\begin{array}{l}\text { SUMMARY OF REFRIGERATOR PERFORMANCE } \\
\text { IN RESPONSE TO TESTED CRITERIA }\end{array}$} \\
\hline Criteria & Impact on Refrigerator Performance \\
\hline Loading density & - No impact on performance \\
\hline $\begin{array}{l}\text { Opening/ closing } \\
\text { refrigerator door }\end{array}$ & $\begin{array}{l}\text { - Good temperature stability preserved throughout door opening trial } \\
\text { - All vials remained within proper storage temperature range throughout } \\
\text { trials } \\
\text { - Most vials experienced only minimal temperature changes in response to } \\
\text { door opening } \\
\text { - Only one vial, which was unpackaged and kept in an open tray, showed } \\
\text { significant temperature spikes }\left(\sim 2^{\circ} \mathrm{C}\right)\end{array}$ \\
\hline Door left ajar & $\begin{array}{l}\text { - Most vials remained within } 2{ }^{\circ} \mathrm{C} \text { to } 8^{\circ} \mathrm{C} \text { even with door propped open for } \\
\text { up to } 1 \mathrm{~h} \\
\text { - Unit features magnetic, self-closing door, so this scenario is unlikely to } \\
\text { occur in real life }\end{array}$ \\
\hline $\begin{array}{l}\text { Increasing room } \\
\text { temperature }\end{array}$ & $\begin{array}{l}\text { - Room temperature changes have very little impact on refrigerator's ability } \\
\text { to maintain internal temperature stability } \\
\text { - To cause internal refrigerator temperature to change by } 1{ }^{\circ} \mathrm{C} \text {, ambient } \\
\text { temperature must vary by }>33^{\circ} \mathrm{C}\end{array}$ \\
\hline Power outage & $\begin{array}{l}\text { - Depending on vial location and storage method, and it takes } 33 \text { min to } 2 \mathrm{~h} \\
25 \text { min for vials to exceed } 8{ }^{\circ} \mathrm{C} \text { after power off } \\
\text { - Unit’s small size = less thermal mass, faster equilibration to ambient } \\
\text { temperatures during an outage } \\
\text { - Power outages pose a greater risk to vaccines stored in small refrigerators, } \\
\text { as they may be exposed to out-of-range temperatures much sooner than } \\
\text { vaccines kept in a full-size unit }\end{array}$ \\
\hline Defrost cycle & $\begin{array}{l}\text { - Automated defrost cycle } \\
\text { - No discernible effect on refrigerator chamber temperature }\end{array}$ \\
\hline $\begin{array}{l}\text { General stability of vial } \\
\text { temperature }\end{array}$ & $\begin{array}{l}\text { - Excellent } \\
\text { - Vaccine vials remained within specified temperature range during regular } \\
\text { operation, regardless of packing density or storage location (except floor), } \\
\text { as well as during door opening trials } \\
\text { - Average vial temperatures varied by less than } 0.5{ }^{\circ} \mathrm{C} \text { throughout entire } \\
\text { range of testing }\end{array}$ \\
\hline
\end{tabular}




\section{ACKNOWLEDGMENTS}

We thank the Centers for Disease Control and Prevention for providing financial support for this project. Additional thanks to Dawn Cross and Wyatt Miller, who assisted with the Vaccines for Children clinic tours.

\section{REFERENCES}

1. Chojnacky, M. J.; Miller, W. W.; Ripple, D. C.; and Strouse, G. F., “Thermal Analysis of Refrigeration Systems Used for Vaccine Storage,” NISTIR 7656, 2009.

2. Chojnacky, M. J.; Miller, W. W.; and Strouse, G. F., "Thermal Analysis of Refrigeration Systems Used for Vaccine Storage,” NISTIR 7753, 2010.

3. Day, G., Rossetto, B., and Ho, J., Testing of Purpose-built Refrigerating Vaccine Storage Cabinets, Test Research Report E175VC-01, Marrickville, New South Wales, 2009.

4. Page, S. L., Earnest, A., Birden, H., Deaker, R., and Clark, C., "Improving vaccination cold chain in the general practice setting," in Australian Family Physician 37, No. 10 (2008).

5. Proceedings of the National Vaccine Storage Workshop, edited by A. Langley, and S. Grant., Queensland Health, Brisbane, 2004.

6. “Performance characteristics of domestic fridges for vaccine storage," E2E IT Solutions Pty. Ltd. Available from: http://www.temptrack.com.au/documents/Fridge Performance Report (Rev A).pdf

7. Vaccine Storage and Handling Toolkit, Centers for Disease Control. Available from: http://www2a.cdc.gov/vaccines/ed/shtoolkit/ 